використанні різних тепло ізолюючих покриттів кокілю. На основі отриманих результатів зроблено висновок про можливість оптимізації параметрів якості поршня шляхом ефективного управліннн процесами кристалізації.

Ключові слова: комп' ютерне моделювання, кокіль, лита деталь, термоізолююче покриттн.

Свген Олександрович Краснокутсъкий, магістрант кафедри ливарного виробнищтва Національного технічного університету «Харківський політехнічний інститут»

\section{THE SIMULATION OF CRYSTALLIZATION IN A METAL MOLD CAST PARTS}

\section{E. Krasnokutskiy}

The results of computer simulation of the сгуstallization process in cast parts of the "piston» by using different insulating coating die Based on the obtained results suggest the possibility of optimizing the parameters of the quality of the piston through the effective management of processes of crystallization.

Keywords: computer modeling, mold, molded part, insulating coating.

Evgeniy Krasnokutskiy, student of foundry, National Technical University «Kharkiv Polytechnic Institute»

\section{Адрес для перелиски:}

61002, г. Харьков, ул. Фрунзе, 21

Национальный технический университет

«Харьковский политехнический институт»

Механико-технологический факультет

E-mail: litvo11@kpi.kharcov.ua

УДК 621.74

Ю. 3. Савченко*

ПРИМЕНЕНИЕ КОМПЬЮТЕРНО-
ИНТЕГРИРОВАННЫХ СИСТЕМ
И ТЕХНОЛОГИЙ В ПРОИЗВОДСТВЕ
ПОРШНЕЙ

В статье приведены результать компьютерного моделирования усадки и формирования усадочных дефектов в литых деталях типа «поршень» при использовании различных термоизолирующих покрытий кокиля. На основании полученных результатов сделан вывод о важности подбора материала теплоизолирующего покрытия для снижения усадочных дефектов.

ключевые слова: литая деталь, покрытие, компьютерно-интегрированная технология.

\section{1. Введение}

Современное состояние вопроса о проектировании деталей ДВС и САПР технологической подготовки производства на одном из определяющих этапах производства деталей ДВС, - изготовления отливок деталей двигателей, - не позволяет говорить об эффективном управлении качеством. Причина этого - не изученность многих процессов, протекающих в процессе формирования отливки, и определяющих, в конечном счете, реальную, а не теоретически спроектированную конструкцию детали.

Поэтому актуальной представляется проблема разработки методологии проектирования деталей ДВС с использованием компьютерно-интегрированных систем и технологий.

Известные западные производители достаточно длительное время при проектировании, техно- логической подготовке и производстве поршней используют компьютерные технологии. Отечественные производители поршней начали использовать компьютерно-интегрированные технологии для решения научных и производственных задач сравнительно недавно [1, 2].

\section{2. Цель исследования и постановка задачи}

В данной работе рассматривается решение проблем по обеспечению качества литых деталей ДВС на примере типа «поршень». Данная деталь была спроектирована в упрощенном виде для простоты анализов результатов ряда экспериментов, выявляющих влияние свойств изолирующего материала кокиля и разделительных составов на процесс образования литейных дефектов. В соответствии

\footnotetext{
* Работа выполнена под руководством профессора Акимова О. В.
} 
с этим необходимо поставить и выполнить следующие задачи:

- создание упрощенной 3D-модели детали типа «поршень» для проведения экспериментов; - моделирование литейных процессов, протекающих при изготовлении поршней из алюминиевых сплавов;

- выявление мест возможного образования дефектов усадочного характера.

\section{3. Методы исследований}

Для проектирования детали типа «поршень» был применен программный пакет трехмерного проектирования Solid Works [3], а для проведения поставленных задач по моделированию литейных процессов была выбрана программа LVM Flow [4-5].

Для постановки задачи была создана конечноразностная модель детали типа «поршень» и металлической оснастки с такими данными:

- размер ячейки - 3 мм;

- количество ячеек - 378480 шт.;

- материал отливки поршня -

АК $12 \mathrm{M} 2 \mathrm{MгH}$ (ГОСТ 1583-93)

(ДСТУ 2839-94);

- предварительный разогрев матриц кокиля и стержня до $t=300{ }^{\circ} \mathrm{C}$;

- поддон кокиля имеет условное водяное охлаждение и разогрет до $t=$ $=100{ }^{\circ} \mathrm{C}$;

- литниковая система представляет собой стояк с щелевым питателем;

- температура металла перед заливкой составляет $-680{ }^{\circ} \mathrm{C}$;

- материал матрицы - серый чугун СЧ20 (ГOCT 1412-85);

- материал стержня и поддона кокиля - углеродистая сталь Сталь45 (ГОСТ 1050-88);

- способ заливки: гравитационное литье (струя): диаметр струи -10 мм; напор -100 мм.

С учетом исходных данных было проведено моделирование процесса дефектов в отливке. При этом варьировались такие параметры как:

1) коэффициент теплопроводности разделительного покрытия, нанесенного на формообразующие поверхности кокиля;

2) материал теплоизоляционного «кожуха», предлагаемого для термоизоляции кокиля.

\section{4. Экспериментальная часть и полученные результаты}

Данное исследование является одним из этапов научно-исследовательской работы, посвященной математическому моделированию и оптимизации технологии изготовления отливок поршней из алюминиевых сплавов. Задача исследования формулируется следующим образом. Задана упрощенная модель отливки типа «поршень» из алюминиевого сплава АК12М2МгН (ГОСТ 1583-93). Необходимо провести оценку влияния материала утеплителя кокиля на процесс образования усадочных дефектов.

Для решения поставленной задачи была выполнена $3 \mathrm{D}-$ модель исходной отливки поршня и элементов технологии литейной формы. 3D-модель строилась с помощью программы Solid Works (рис. 1).

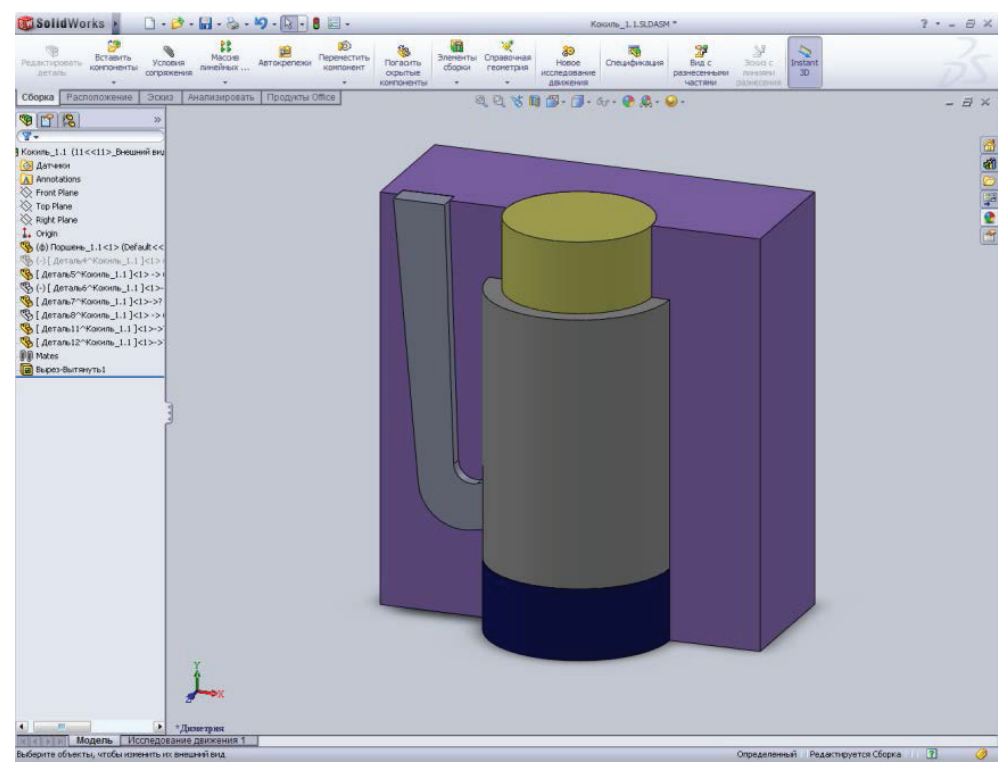

Pис. 1. Упрощенная 3D-модель отливки типа «поршень» и элементов технологии литейной формы

Далее была выполнена конвертация в формат программы LVMFlow и выполнены эксперименты № 1-А, 1-Б (табл. 1) с целью выявления возможных дефектов и мест их локализации. «Пролитая» с помощью LVMFlow модель имеет вид, представленный на рис. 2-3.

Таблица 1

Условия эксперимента

\begin{tabular}{|c|c|c|}
\hline № расчета & $\begin{array}{c}\text { Толщина слоя - } \\
5, \text { мм }\end{array}$ & $\begin{array}{c}\text { Коэффицциент тепло- } \\
\text { проводности, } \lambda, \text { Вт/м }{ }^{\circ} \mathrm{C}\end{array}$ \\
\hline 1-А & 0,3 & 0,002 \\
\hline 1-Б & 0,3 & 0,4 \\
\hline
\end{tabular}

При данных начальных условиях и выбранных коэффициентах теплопроводности разделительных составов в процессе моделировании были получены картины образования усадочных дефектов, представленные на рис. 2-3.

После анализа результатов моделирования усадки можно утверждать, что в случае применения «виртуального» разделительного состава с высокими теплопроводящими свойствами усадочные 


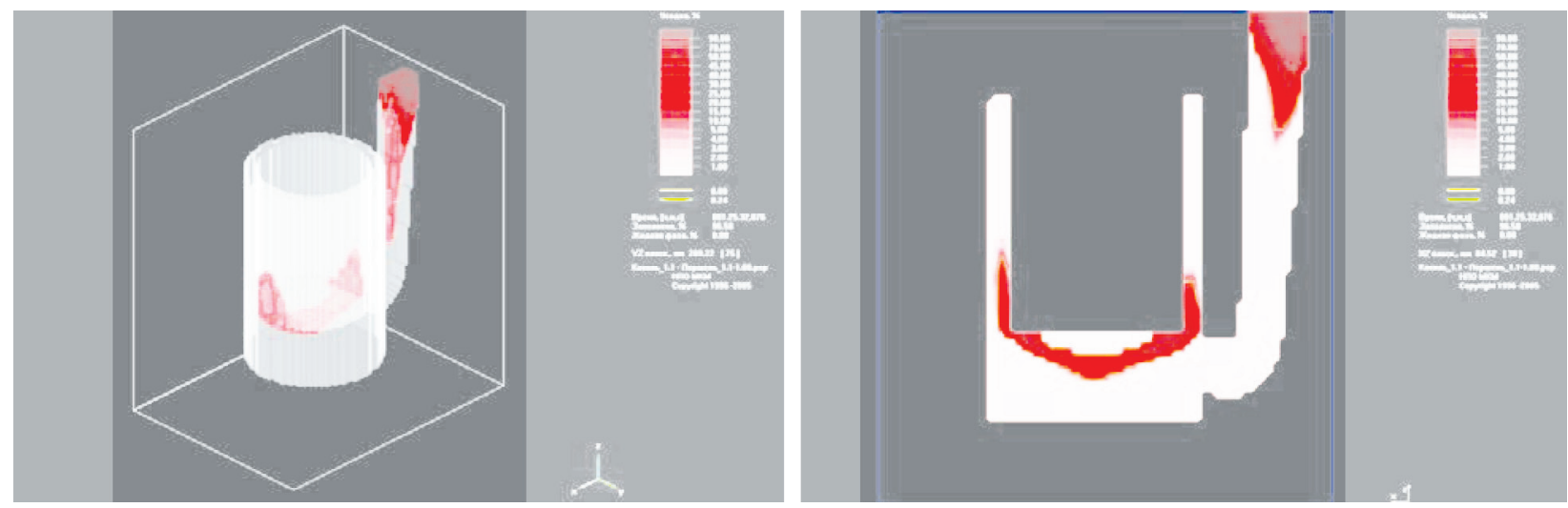

Pис. 2. Результаты моделирования (расчет 1-А)
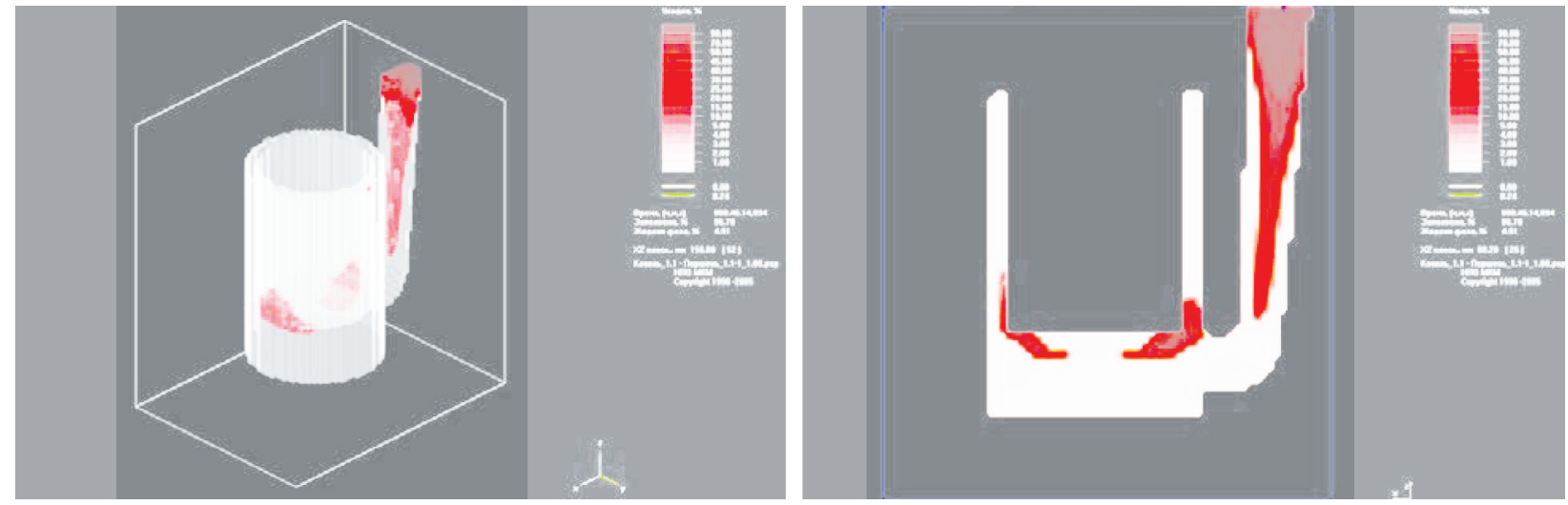

Pис. 3. Результаты моделирования (расчет 1-Б)

дефекты изменили характер локализации на рассредоточенный. Однако вероятность образования и локализация дефектов усадочного характера не изменились.

Таким образом, было установлено, что применение разделительных составов с кардинально разными теплоизоляционными свойствами в теле отливки формируются дефекты - усадочная пористость, локализованная в двух местах отливки.

В качестве второго этапа расчетов были выбраны 3 альтернативных пути устранения пористости, путем применения термоизолирующего кожуха (рис. 4), покрывающего кокиль:

1. Материал кожуха с высокими теплоаккумулирующими свойствами (виртуальный) $\lambda=$ $=0,001 ; S_{1}=10 \mathrm{мм} ; S_{2}=40 \mathrm{мм}$.

2. Материал кожуха с высокой теплопроводностью (асбестовый картон) $\lambda=0,2 ; S_{1}=10$ мм; $S_{2}=40$ мм.

3. Применить вариант использования обоих материалов, для утепления различных частей кокиля одновременно.

Все три варианта были промоделированы. Общие начальные условия оставались прежними, однако свойства и толщина разделительного слоя оставались в последующих расчетах постоянными, а варьировались свойства материала кожуха (табл. 2). Результаты моделирования для расчетов 2-А и 2-Б представлены на рис. 5-6 соответственно.

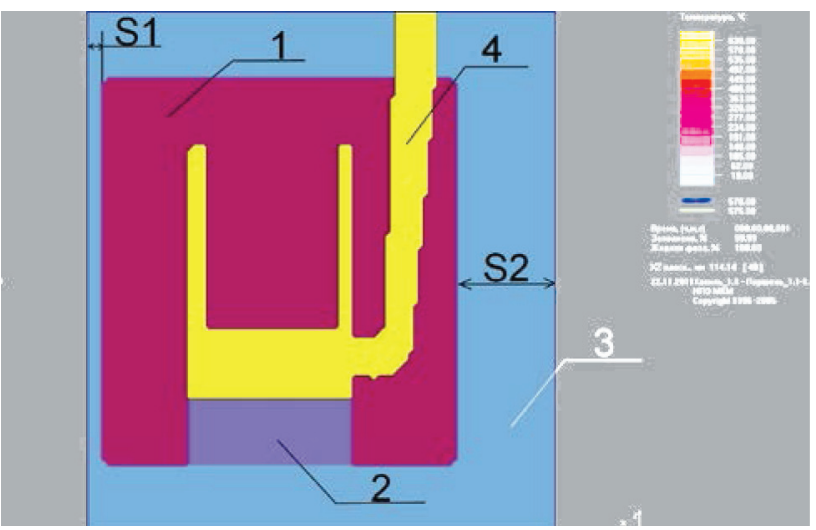

Pис. 4. Гечение кокиля с теплоизолирующим кожухом: 1 - кокиль, 2 - поддон, 3 - теплоизолирующий кожух

Таблица 2

Условия эксперимента

при варьировании свойства материала кожуха

\begin{tabular}{|c|c|c|c|l|}
\hline $\begin{array}{c}\text { № рас- } \\
\text { чета }\end{array}$ & $S_{1, \text { мм }}$ & $S_{2, \text { мм }}$ & $\lambda$, Вт/м & \multicolumn{1}{|c|}{ Материал } \\
\hline $2-А$ & 10 & 40 & 0,001 & виртуальный \\
\hline $2-5$ & 10 & 40 & 0,2 & асбестовый картон \\
\hline $2-В$ & 10 & 40 & $0,001-0,2$ & комбинированный \\
\hline $2-Г$ & 10 & 40 & 0,085 & пеностекло \\
\hline
\end{tabular}

Анализ результатов моделирования процесса усадки в отливке показал, что применение материа- 

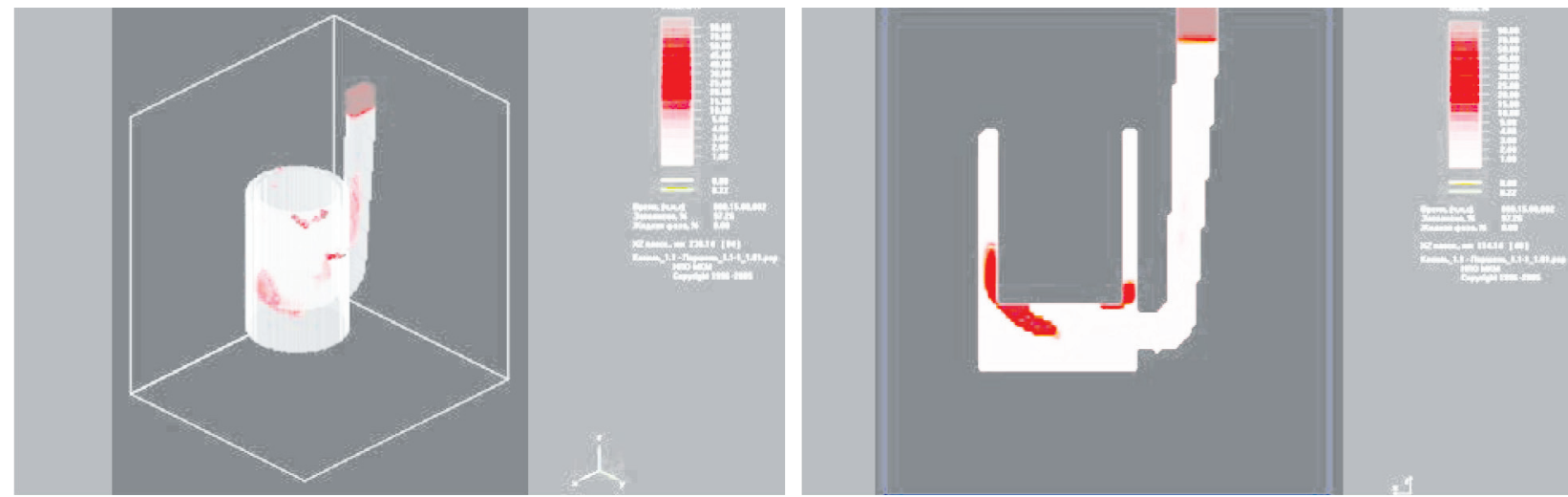

Рис. 5. Результаты моделирования при использовании в качестве разделительного слон виртуального материала
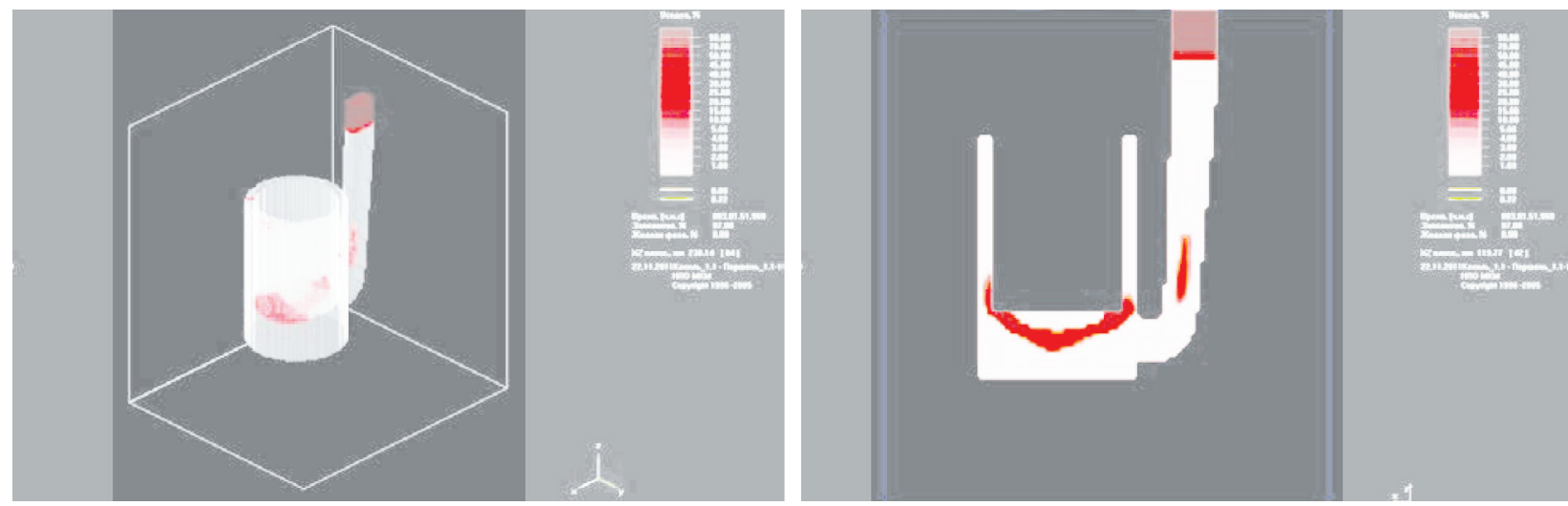

Pис. 6. Результаты моделирования при использовании в качестве разделительного слон асбестового картона

лов с кардинально различными экстремальными значениями коэффициента теплопроводности для использования в качестве теплоизолирующего кожуха не пригодны, т. к. их внедрение приводит к результатам, аналогичным применению разделительных составов, рассмотренных выше.

На рис. 7 приведена схема размещения различных материалов теплоизолирующего кожуха для моделирования образования усадочных дефектов. Как видно из рис. 7, для кокиля использовался теплоизолирующий кожух, состоящий из двух равных частей, выполненных из материалов с разными экстремальными коэффициентами теплопроводности (табл. 2).

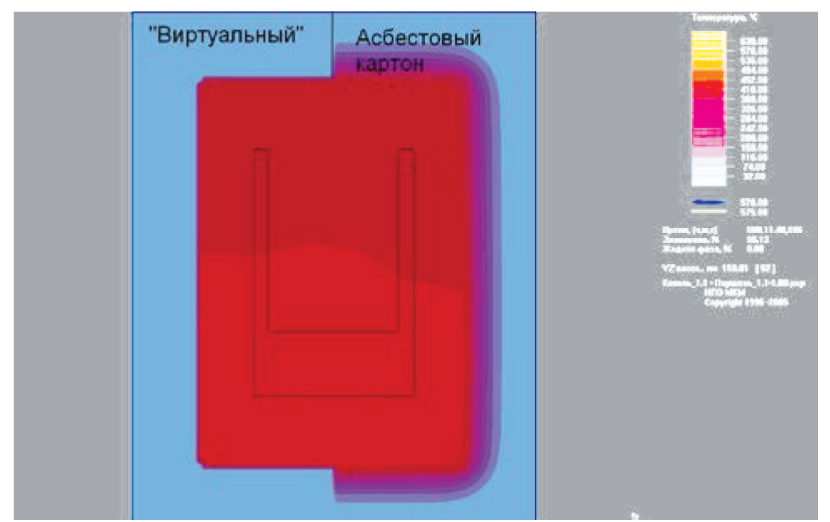

Рис. 7. Схема размещения различных материалов теплоизолирующего кожуха
Графический результат моделирования процесса образования усадочных дефектов в отливке (расчет 2-В, табл. 2) представлен на рис. 8.

После анализа результатов экспериментов с применением материалов утеплителя кокиля с различными теплопроводящими свойствами было решено провести расчет процесса кристаллизации и образования дефектов с применением материала утеплителя, имеющего усредненные, по сравнению с рассмотренными выше материалами, теплопроводящими свойствами.

«Блоки и плиты из пеностекла FOAMGLAS ${ }^{\circledR} \gg$ : $\lambda=0,085 ; S_{1}=10 \mathrm{mм} ; S_{2}=40 \mathrm{мм}$.

Полученный результат (расчет 2-Г, табл. 2) представлен на рис. 9.

Полученные результаты компьютерного моделирования могут быть использованы в качестве экспериментальных точек плана эксперимента для построения математических моделей, связывающих параметры покрытия и качество получаемых отливок, на основании которой возможна оптимизация этих параметров и выдача практических рекомендаций по совершенствованию техпроцессов в промышленное производство [3, 8-10].

\section{5. Выводы}

На основе рассмотрения и моделирования влияния теплоизоляционного кожуха и разделительных 

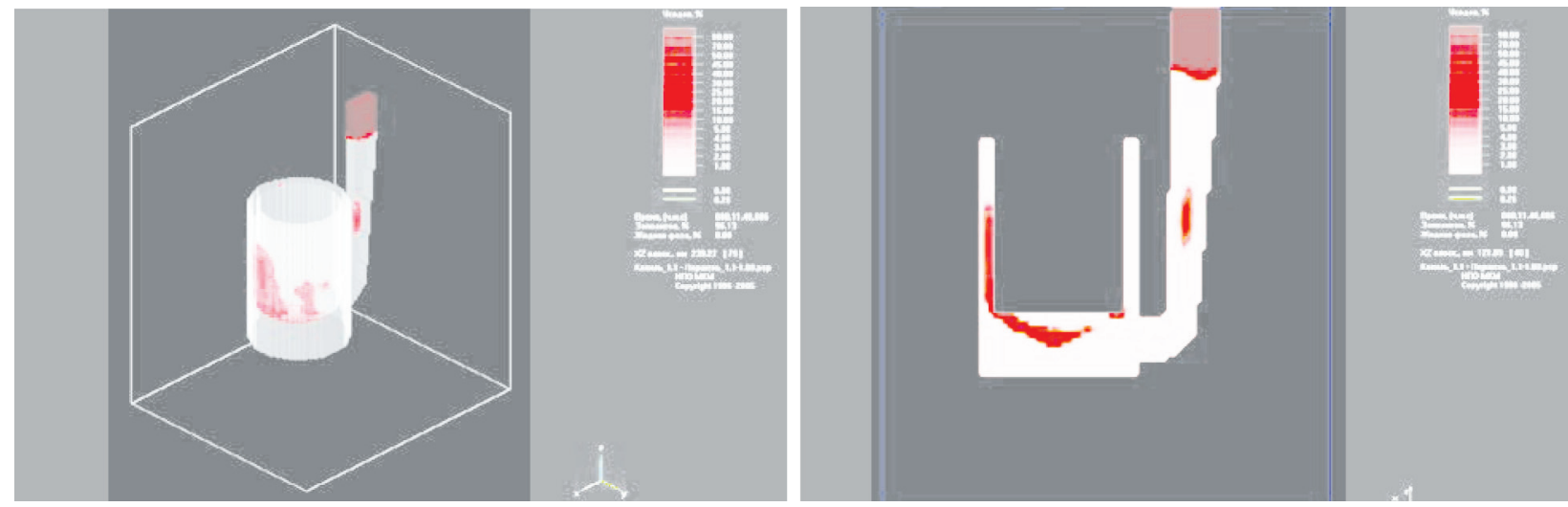

Pис. 8. Графический результат моделирования процесса образованин усадочных дефектов в отливке при использовании комбинированного теплоизолирующего кожуха
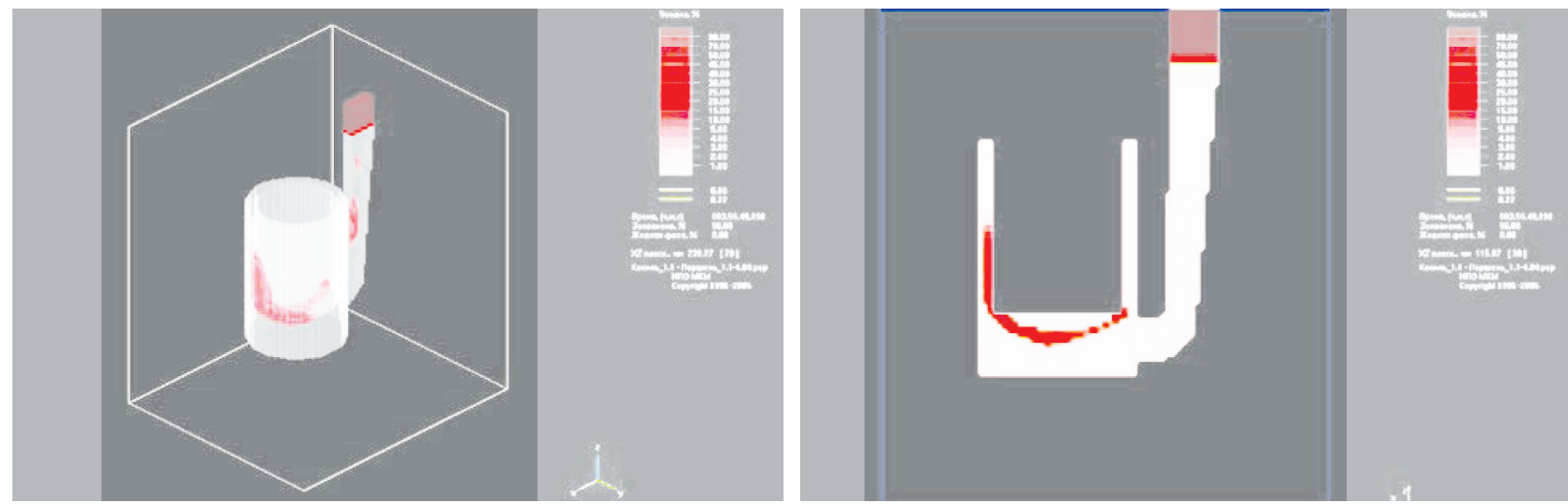

Pис. 9. Результат компьютерного моделирования процесса усадки (пеностекло: $\lambda=0,085 ; S_{1}=10$ мм; $S_{2}=40$ мм)

составов на формообразующих поверхностях с различными теплофизическими свойствами на процесс образования дефектов усадочного характера показана важная роль материала покрытия в формировании качественных литых деталей типа «поршень».

\section{Литература}

1. Титов Н. Д. Технология литейного производства [Текст] / Н. Д. Титов, Ю. А. Степанов. - М. : Машиностроение, 1985. - 404 с.

2. Могилев В. К. Справочник литейщика [Текст] / В. К. Могилев, О. И. Лев. - М. : Машиностроение, 1988. - 274 с.

3. Дёмин Д. А. Обработка экспериментальных данных и построение математической модели технологического процесса методом наименьших квадратов (МНК) [Текст] / Д. А. Дёмин. - Восточно-Европейский журнал передовых технологий. - Х. : Технологический Центр. - 2006. № 3/1. - C. 47-50.

4. Алёхин В. И. Моделирование мест проявления дефектов усадочного характера при проектировании литых деталей ДВС [Текст] / В. И. Алёхин, А. В. Белогуб, А. П. Марченко, О. В. Акимов // «Металл и литье Украины». - Киев. - 2010. № 12. - С. 27-30.
5. Алёхин В. И. Компьютерное моделирование процессов при производстве литых деталей двигателя [Текст] / В. И. Алёхин, О. В. Акимов, А. П. Марченко // Международный научнотехнический журнал «Литейное производство». Москва. - 2010. - № 9. - С. 31-33.

6. Алёхин В. И. Компьютерно-интегрированное моделирование литейных процессов в автомобильных поршнях на основе конструкторско-технологической методики проектирования деталей ДВС [Текст] / В. И. Алёхин, А. В. Белогуб, А. П. Марченко, О. В. Акимов // Научно-технический журнал «Двигатели внутреннего сгорания». - Харьков : НТУ «ХПИ». - 2009. № 2. - С. 101-104.

7. Алёхин В. И. Моделирование литейных процессов при изготовлении автомобильных поршней [Текст] / В. И. Алёхин, А. В. Белогуб, А. П. Марченко, О. В. Акимов // Ежемесячный научно-технический и производственный журнал «Цветные металлы». - Москва. - 2010. - № 8. - С. 81-83.

8. Коваленко Б. П. Оптимизация состава холоднотвердеющих смесей (ХТС) с пропиленкарбонатом [Текст] / Б. П. Коваленко, Д. А. Дёмин, А. Б. Божко. - Восточно-Европейский журнал передовых технологий. - Х. : Технологический Центр. - 2006. - № 6. - С. 59-61. 
9. Дёмин Д. А. Оптимизация технологического процесса в цехе предприятия [Текст] / Д. А. Дёмин. Восточно-Европейский журнал передовых технологий. - Х. : Технологический Центр. - 2005. № 6. - С. 48-59.

10. Дёмин Д. А. Оптимизация технологических режимов [Текст] / Д. А. Дёмин. - Восточно-Европейский журнал передовых технологий. - Х. : Технологический Центр. - 2006. - № 2/1(20). C. $32-35$.

\section{ВИКОРИСТАННЯ КОМП'ЮТЕРНО-ІНТЕГРОВАНИХ СИСТЕМ ТА ТЕХНОЛОГІЙ У ВИРОБНИЦТВІ ПОРШНВВ}

\section{Ю. Е. Савченко}

У статті наведені результати комп' ютерного моделювання усадки та формүвання усадкових дефектів в литих деталнх типа «поршень» при використанні різних термоізолюючих покриттів кокіля. На основі отриманих результатів зроблено висновок про важливість підбору матеріалу термоізолюючого покриття для зниження усадкових дефектів.

Ключові слова: лита деталь, покриттн, комп'ютерноінтегрована технологін.

Юлія Едуардівна Савченко, магістрант кафедри ливарного виробництва Національного технічного університету «Харківський політехнічний інститут»

\section{USE OF COMPUTER-INTEGRATED SYSTEMS AND TECHNOLOGY IN THE PRODUCTION OF PISTONS}

\section{Y. Savchenko}

The results of computer simulation of shrinkage and the formation of shrinkage defects in castings of the "piston" by using different insulating coating die. Based on the obtained results suggest the importance of selecting the material insulating coating to reduce shrinkage defects.

Keywords: molded piece, cover, computer-integrated technology.

Yuli Savchenko, student of foundry, National Technical University «Kharkiv Polytechnic Institute»

\section{Адрес для перелиски: \\ 61002, г. Харьков, ул. Фрунзе, 21 \\ Национальный технический университет \\ «Харьковский политехнический институт» \\ Механико-технологический факультет \\ E-mail: litvo11@kpi.kharcov.ua}

В. I. Логаніна,
В. Г. Камбург,
Т. В. Учаева

\section{УДОСКОНАЛЕННЯ СИСТЕМИ КОНТРОЛЮ ЯКОСТІ БУДІВЕЛЬНИХ MATEPIAЛIB TA BИPOEIB}

У статті наведено відомості про застосування індексів відтворюваності процесу в системі контролю якості продукції на підприємствах будіндустрії. Викладено результати розрахунку відсотка браку продукції при різних значеннях центрованості процесу виробництва.

Ключові слова: система контролю, відтворюваність прочесу, брак, варіації, виробництво бетону.

Існуюча в даний час система контролю якості будівельної продукції на підприємствах будівельної індустрії, що передбачає застосування вхідного, операційного та приймального контролю, часто оцінює налагодженість процесу виробництва за параметрами, що входять в поле допуску відповідно до чинної нормативної документації. Досвід показує, що якщо значення міцності бетону, які визначаються лабораторією або ВТК, знаходяться в межах $H \Gamma<R_{i}<B \Gamma$, то така ситуація не викликає стурбованості служб контролю.

Між тим, будь-який процес виготовлення продукції пов'язаний з варіаціями його параметрів, викликаних великою кількістю факторів, які впливають на нього. У той же час, розкид показників якості, навіть якщо вони знаходяться в межах допуску, може привести до збільшення браку та додаткових фінансових витрат [1].

При наладці технологічних процесів зазвичай налаштовують процес таким чином, щоб середнє $\bar{x}$, збігалося або було близько до цільового значення $x_{0}$, або зменшують розкид значень характеристики навколо свого середнього $\bar{x}$, тобто потрібне виконання наступних моментів:

- процес виробництва повинен знаходитися

в статистично керованому стані; 